ROCZNIKI TEOLOGICZNE

Tom LXVII, zeszyt $11-2020$

DOI: https://doi.org/10.18290/rt206711-7

KS. JERZY KOSTORZ

\title{
ICT IN DER THEOLOGISCH-RELIGIÖSEN AUSBILDUNG POLNISCHER RELIGIONSLEHRER*INNEN
}

\author{
ICT IN THE FORMATION OF POLISH CATECHISTS TODAY
}

\begin{abstract}
A b s tra ct. With the development of new information and communication technologies in Poland and the digitization of Polish schools, an attempt was made to present ICT as used in the contemporary formation of Polish catechists. Reference was made to the catechetical documents of the universal Church and in Poland, normative acts and literature of the subject. Attention was paid to both initial and permanent formation. For this purpose, a short presentation was made of the current state of the formation of catechists in Poland regarding ICT. Next, the status and functions of ICT in the formation of Polish catechists were analyzed and the ways of its implementation. This showed that ICT has a special place in the contemporary formation of Polish catechists. ICT is indispensable for catechists because only in this way can they enhance their IT skills. At the same time a number of e-learning options were presented, as well as the possibilities that ICT opens for catechists working in schools regarding lesson organization and methodology. Also, the article shows the importance of the ability to use remote learning platforms (e.g., Storybird, Padlet, Story Dice) and create and use various applications (such as LearningApps.org., Kahoot!).
\end{abstract}

Keywords: didactics of catechesis; religion teacher; catechist; theological and religious formation; ICT; e-learning.

Es ist unstrittig, dass die Informations- und Kommunikationstechnologien zu den wichtigsten Herausforderungen gehören, mit denen die theologisch-religiöse Ausbildung polnischer Religionslehrer*innen konfrontiert wird. Die Covid-19-Pandemie hat das mit aller Deutlichkeit bestätigt. In einer Situation, in welcher der Präsenzunterricht nicht mehr möglich war, wurden alle Lehrkräfte, auch Religionslehrinnen und -lehrer, gehalten, auf E-Learning umzustellen, was leider

Jerzy Kostorz, habil. Dr., Prof. UO, Abteilung für Pastoraltheologie, Katechetik, Pädagogik und Psychologie, Universität Opole; Korrespondenzadresse: Pl. Kopernika 11A, 45-040 Opole, Polen; e-mail: jkostorz@uni.opole.pl; ORCID: https://orcid.org/0000-0003-4817-2816. 
nicht immer und überall optimal funktionierte. Das beklagten übereinstimmend Lehrende und Eltern. Auch die Schüler*innen waren mit ihrem digitalen Unterricht unzufrieden. Daraus lässt sich schließen, dass sich der ,normale“ Unterricht im Vergleich zum digitalen größerer Beliebtheit erfreut. Dafür gibt es mit mehrere Gründe. Zu den wichtigsten gehören das Fehlen passender E-Learning-Plattformen und entsprechender Unterrichtshilfen. Doch auch die besten Tools werden ohne Lehrkräfte, die mit IC-Technologien kompetent umgehen können, ihr Ziel verfehlen. Dieser Vorbehalt trifft auch auf Religionslehrer*innen in Polen zu.

So ist $\mathrm{zu}$ fragen, welche Rolle heute IC-Technologien bei der geistlichen Formung polnischer Religionslehrerinnen und Religionslehrer spielen und ob und in welchem Maße sie darin ihre Wirkung entfalten. Dabei geht es vor allem um die Bedeutung und Rolle, die ICT bei der Förderung der fachlichen Kompetenzen der angehenden Katechetinnen und Katecheten zukommt. Um diese Frage beantworten zu können, ist zunächst die einführende und permanente Formung und dann die Methodik des Religionsunterrichts zu analysieren. Beide Aspekte werden uns die Bestimmung ermöglichen, wie eine moderne theologisch-religiöse Ausbildung künftiger Katechet*innen aussehen sollte, in deren Rahmen sie auf die Verwendung von ICT vorbereitet würden. Natürlich ist sie ohne den Einsatz von E-Learning, sowohl in der einführenden als auch in der permanenten geistlichen Formung, nicht möglich. Um dieses Ziel zu erreichen, werden katechetische Dokumente der katholischen Kirche und der Kirche in Polen sowie normative Akte und Gegenstandsliteratur gesichtet.

Unter der im Titel angeführten Abkürzung $\mathrm{ICT}^{1}$ (Information and Communication Technologies) sind alle Technologien zu verstehen, die der Verarbeitung, Speicherung und Übertragung von Informationen in elektronischer Form dienen. ${ }^{2}$ In der Praxis bedeutet das u. a. die Arbeit mit interaktiven Whiteboards und ihrer Software, Computerprogrammen, Online-Tools und Apps, die im Internet verfügbar sind. ${ }^{3}$ Auch der Informationsaustausch zwischen den am Bildungsprozess Beteiligten (Lehrende - Lernende; Schüler*innen als Klassenverband) bzw. zwischen den Lernenden und dem Gerät in digitaler Form (Onlineformulare, E-Mails, E-Arbeitsblätter, Kommunikationsprogramme) wird

\footnotetext{
${ }^{1}$ Siehe etwa Renata SEWERYN, „Technologie informacyjne i komunikacyjne - wprowadzenie“, in Technologie informacyjne i komunikacyjne na rynku turystycznym, hrsg. v. Jadwiga Berbeka und Krzysztof Borodako (Warszawa: C.H. Beck, 2017), 14-15; vgl. etwa Marian ZAJĄC, „Możliwość wykorzystania technologii informacyjno-komunikacyjnych w edukacji religijnej“, Biuletyn Edukacji Medialnej, Nr. 2 (2015): 85-96.

${ }^{2}$ SEWERYN, „Technologie informacyjne i komunikacyjne“, 14-15.

3 „ICT - Technologie informacyjno-komunikacyjne“, istshare, abgerufen am 30. April 2020, https://www.istshare.eu/ict/technologie/informacyjno/komunikacyjne.html.
} 
zum ICT-Instrumentarium gerechnet. Das Wesen einer so verstandenen IC-Technologie machen ihr moderner Charakter, ihre leichte Verfügbarkeit und die Aktivierung aller Beteiligten aus. ${ }^{4}$ Dabei gilt es zu bedenken, dass sich ICT nicht nur auf PCs und interaktive Whiteboards beschränkt, sondern dass sie auch Digitalkameras, Smartphones, Tablets, iPhones, iPads und Smartwatches umfasst ${ }^{5}$ Häufig handelt es sich dabei um mobile Geräte, die sich im Besitz der Lehrkräfte und Lernenden befinden. Sie sind mit Kamera, Mikrofon, Lautsprecher, Diktiergerät ausgestattet und verfügen über einen Touchscreen, der die Arbeit mit jüngeren Kindern sehr erleichtert, weil man sich leichter auf die Vermittlung von Inhalten kann und sich nicht so sehr auf die technische Bedienung der Geräte konzentrieren muss. ${ }^{6}$

Mit unseren Überlegungen wollen wir vor allem nachweisen, dass angehende Religionspädagog*innen auf den Einsatz von ICT sowohl im Homeschooling als auch im Präsenzunterricht vorbereitet werden sollten. Die für den Ausbildungsprozess Verantwortlichen sollten Voraussetzungen für den Erwerb von Kompetenzen im Bereich Informatik schaffen. Dabei geht es nicht nur um das Suchen, Ordnen und Nutzen von Informationen aus diversen Quellen, sondern auch um die Anwendung dieser Tools in der einführenden und danach in der permanenten Phase. Diese Kompetenzen sollten später im eigenen Religionsunterricht in der Schule abgerufen werden. In diesem Zusammenhang stellt sich jedoch die Frage nach dem Wie der theologisch-religiösen Ausbildung, damit Katechetinnen und Katecheten Informatikkompetenzen erwerben und entfalten können? Die Antwort auf diese Frage erfordert zunächst eine kurze Diagnose der aktuellen einführenden und permanenten geistlichen Formung der künftigen Religionslehrerinnen und Religionslehrer in Polen.

\section{DIAGNOSE DER THEOLOGISCH-RELIGIÖSEN AUSBILDUNG DER RELIGIONSLEHRER*INNEN IN POLEN}

Das aktuell geltende System der Ausbildung polnischer Religionslehrer*innen ist in vieler Hinsicht einheitlich und wird sowohl durch entsprechende katechetische Dokumente der römisch-katholischen Kirche als auch staatliche normative Akte über die Aus- und Fortbildung von Lehrkräften geregelt. Dies betrifft auch Fragen der ICT. Zu den kirchlichen Dokumenten

\footnotetext{
${ }^{4}$ Ebd.; SEWERYN, „Technologie informacyjne i komunikacyjne“, 14-15.

5 „Kilka słów o TIK“, Tik w szkole602642223 (Blog), 17. März 2018, abgerufen am 30. April 2020, https://tikwszkole602642223.wordpress.com/2018/03/17/kilka-slow-o-tik.

${ }^{6}$ Ebd.
} 
gehören vor allem: Dyrektorium ogólne o katechizacji ${ }^{7}$, Dyrektorium katechetyczne Kościoła katolickiego w Polsce ${ }^{8}$, Porozumienie pomiędzy Konferencją Episkopatu Polski oraz Ministerstwem Edukacji Narodowej z 3 kwietnia 2019 w sprawie kwalifikacji zawodowych wymaganych od nauczycieli religii. ${ }^{9}$ Zur Gruppe der staatlichen Dokumente gehören: Ustawa z dnia 7 września $1991 \mathrm{r}$. o systemie oświaty ${ }^{10}$, Ustawa z dnia 14 grudnia 2019 - Prawo oświatowe ${ }^{11}$, Ustawa z dnia 26 stycznia 1982 - Karta Nauczyciela ${ }^{12}$, Rozporządzenie Ministra Nauki i Szkolnictwa Wyższego z dnia 25 lipca 2019 w sprawie standardu kształcenia przygotowującego do wykonywania zawodu nauczyciela ${ }^{13}$, Rozporządzenie Ministra Edukacji Narodowej z dnia 26 lipca 2018 w sprawie uzyskiwania stopni awansu zawodowego przez nauczycieli ${ }^{14}$ und Rozporządzenie Ministra Edukacji Narodowej z dnia 23 sierpnia 2019 zmieniająca rozporządzenie w sprawie uzyskiwania stopni awansu zawodowego przez nauczycieli. ${ }^{15}$

Die oben genannten katechetischen Dokumente und Rechtsakte definieren die Qualität und Modalitäten der theologisch-religiösen Ausbildung von Religionslehrern*innen in Polen. In den kirchlichen Dokumenten sowie im Abkommen zwischen der Bischofskonferenz und dem Bildungsminister wird der Einsatz von ICT zwar nicht direkt erwähnt, trotzdem wird darin die notwendige Anpassung der geistlichen Formung der angehenden Religionslehrer*innen an die jeweiligen aktuellen Erfordernisse sowie an pädagogische und katechetische Herausforderungen betont. ${ }^{16}$ Neue methodische Erkenntnisse werden darin als wichtig gewürdigt. Zusammenfassend darf also gesagt werden, dass der Einsatz von ICT und die Vorbereitung der Katecheten auf die Anwendung von

\footnotetext{
${ }^{7}$ KongREGATION FÜR DEN KLERUS, Dyrektorium ogólne o katechizacji [Allgemeindirektorium über Katechisierung] (Poznań: Pallottinum, 1998).

${ }^{8}$ Polnische BischofsKonferenz, Dyrektorium katechetyczne Kościoła katolickiego $w$ Polsce [Katechetisches Direktorium der katholischen Kirche in Polen] (Kraków: WAM, 2001).

${ }^{9}$ Abkommen zwischen der polnischen Bischofskonferenz und dem Ministerium für Nationale Bildung vom 3. April 2019 über die beruflichen Anforderungen an Religionslehrer*innen], Dziennik Urzędowy MEN 2019, Pkt. 9.

${ }^{10}$ Gesetz vom 7. September 1991 über das Bildungssystem, Einheitlicher Text: Dziennik Ustaw 2019, Pkt. 1481, 1818, 2197.

${ }^{11}$ Gesetz vom 14. Dezember 2019 - Bildungsrecht, Einheitlicher Text: Dziennik Ustaw 2019, Pkt. 1148,1078,1287, 1680, 1681, 1818 2197, 2248, und 2020, Pkt. 374.

12 Gesetz vom 26. Januar 1982 - Lehrercharta, Einheitlicher Text: Dziennik Ustaw 2019, Pkt. 2215.

${ }^{13}$ Verordnung des Ministers für Wissenschaft und Hochschulwesen vom 25. Juli 2019 über Ausbildungsstandards für den Lehrerberuf, Dziennik Ustaw 2019, Pkt. 1450.

${ }^{14}$ Verordnung des Ministers für Nationale Bildung vom 26. Juli 2018 über die Beförderung von Lehrern, Dziennik Ustaw 2018, Pkt. 1547.

${ }^{15}$ Verordnung des Ministers für Nationale Bildung vom 23. August 2019 über Änderungen der Verordnung über die Beförderung von Lehrern, Dziennik Ustaw 2019, Pkt. 1650.

${ }^{16}$ Kongregation fÜr DEn Klerus, Dyrektorium ogólne o katechizacji, Nr. 242, 244.
} 
modernen Tools in der Didaktik, Erziehung und im Religionsunterricht indirekt als wichtig angesehen wird.

Im Hinblick auf die beruflichen Qualifikationen der Religionslehrer*innen beruft sich die katholische Kirche auf das polnische Bildungsgesetz. ${ }^{17}$ Die Anforderungen im Bereich Informatik sind erheblich und in den bereits erwähnten normativen Akten geregelt, in denen die Aus- und Fortbildungsstandards für die Lehrerausbildung festgelegt sind. Demzufolge ist das aktuelle System der Formung von Religionslehrern*innen von der theoretischen Seite her im Großen und Ganzen positiv und korrekt. Es beinhaltet Antworten auf die gegenwärtigen Herausforderungen und kommt den Erwartungen der Kinder und Jugendlichen sowie der jüngsten Generation der Religionslehrer*innen durchaus entgegen. in der Praxis lassen sich jedoch schon bei einer flüchtigen Beobachtung der praktischen Umsetzung der geltenden Vorschriften und einer Analyse der Aus- und Fortbildungsangebote der theologischen und katechetischen Fakultäten sowie der methodischen Beratungsstellen für den Religionsunterricht einige Abweichungen feststellen. Sie betreffen u. a. die unterschiedliche Zahl der ICT gewidmeten Unterrichtstunden, die curricularen Inhalte und ihre Umsetzung im Unterricht sowie unterschiedliche Formen der Fortbildung. Diese Differenzen wären an sich nicht negativ, wenn sie nicht die ICT-Ausbildung an den Hochschulen von der Fortbildung der bereits berufstätigen Lehrkräfte separieren würden. Darüber hinaus sollte die einführende und permanente ICT-Ausbildung auf pädagogische Erwartungen und gegenwärtige Herausforderungen antworten. Leider haben wir es in der Praxis mit verschiedenen Ansätzen zu tun. In vielen Fällen dominieren nach wie vor traditionelle Unterrichtsformen (Frontalunterricht, direkt) mit Vortrag und anschließendem Gespräch. Viele Institutsleiter, Dozenten und Mitarbeiter der Fakultäten für Religionspädagogik und der Fortbildungsanstalten interessieren sich kaum für die ICT-Problematik. Auch die Autorinnen und Autoren neuer Lehrbücher interessieren sich eher selten für moderne Unterrichtsformen und eine breitere Berücksichtigung von ICT im Religionsunterricht. Aus diesem Grund sind dann die Lehrkräfte auf ihre eigenen Möglichkeiten und Einschränkungen (z. B. finanzielle, formale) zurückgeworfen.

Im Endeffekt ist E-Learning bei der Ausbildung der Religionslehrinnen und -lehrer in Polen eher eine Seltenheit. Vereinzelte Elemente, hauptsächlich im Grundstudium (an theologischen Fakultäten), wurden während der Covid19-Pandemie aufgegriffen. Ihre Anwendung beschränkte sich jedoch nur auf

\footnotetext{
${ }^{17}$ Abkommen zwischen der polnischen Bischofskonferenz und dem Ministerium für Nationale Bildung vom 3. April 2019, Pkt. 9.
} 
die Nutzung von E-Learning-Plattformen, Kommunikationsprogrammen und Emails. Die Inhalte blieben davon unberührt. Dabei ist es nicht einfach, Wissen und ICT-Fertigkeiten, ohne die Verwendung moderner Tools zu vermitteln. Somit ist das gegenwärtig geltende Ausbildungssystem immer noch sehr stark in der Vergangenheit und Tradition behaftet und bleibt organisatorisch, formell und methodisch von der neuen, sich ständig verändernden Wirklichkeit, unberührt. An dieser Einschätzung ändern auch die Ergebnisse fragmentarischer Untersuchungen an einer ausgewählten Gruppe von Religionslehrern nichts, mit deren Hilfe man nachzuweisen versucht, dass die gegenwärtige Ausbildung richtig und mit den Anforderungen einer digitalen Schule kompatibel sind. Vielmehr bedarf die Frage der Anwendung von ICT im Prozess der Ausbildung von Religionslehrer*innen in Polen einer Untersuchung an einer repräsentativen Gruppe. Allein auf der Grundlage solcher Untersuchungen werden neue Curricula vorbereitet werden können. Angesichts der gegenwärtigen pädagogischen Herausforderungen ist heute eine Neubewertung des Stellenwerts und der Funktion von ICT im Ausbildungsprozess notwendig. Es steht außer Frage, dass der Einsatz von IC-Technologien heute unverzichtbar ist und alle Lehrkräfte über ausreichende Informatikkompetenzen verfügen müssen.

\section{STELLENWERT UND FUNKTIONEN VON ICT IN DER THEOLOGISCH-RELIGIÖSEN AUSBILDUNG VON RELIGIONSLEHRER*INNEN}

Es dürfte wohl kein Zweifel darüber bestehen, dass IC-Technologien eine wichtige Rolle bei der Ausbildung von Religionslehrerinnen und -lehrern spielen sollten. Sie sind als wichtiges Element sowohl in der einführenden als auch der permanenten Formung anzusehen. Dabei geht es nicht darum, bisherige Formen durch neue zu ersetzen, sondern um Aufwertung und Verwendung von IC-Technologien ${ }^{18}$, die Hochschuldozenten, leitende Mitarbeiter der Fakultäten, Methodiker, Experten sowie Studierende und Religionslehrer*innen bei ihrer Arbeit unterstützen. Im Einklang mit dem Wandel im Schulwesen handelt es sich hier um eine interaktive Hilfe im Lehr- und Lernprozess ${ }^{19}$ sowie um den Erwerb von neuen Kenntnissen und Fertigkeiten. Die Adressaten

\footnotetext{
${ }^{18}$ Siehe mehr dazu in Anna Zellma, Profesjonalny rozwój nauczyciela religii (Olsztyn: Wydział Teologii Uniwersytetu Warmińsko-Mazurskiego w Olsztynie), 280-94.

${ }^{19}$ Siehe und vgl. Paweł MĄKOSA, „Nauczanie wobec cyfryzacji polskiej szkoły“, Roczniki Teologiczne 61, Nr. 11 (2014): 25-38.
} 
dieser Maßnahmen sollten als handelnde Subjekte unter Zuhilfenahme von ICT agieren, während die Lehrenden die Rolle von Animatoren und Moderatoren einnehmen. ICT bedeutet lediglich eine attraktive Form der Durchführung einzelner Etappen während der einführenden und permanenten Formung. Hier halten wir noch einmal fest, dass mit diesem Instrumentarium traditionelle Formen keineswegs dominiert oder ersetzt werden sollen.

Der Einsatz von ICT in der einführenden und permanenten Phase der geistlichen Ausbildung angehender Religionslehrerinnen und -lehrer muss stets begründet sein. Sie sollte eine aktivierende Rolle spielen und Studierende bzw. bereits aktive Lehrkräfte zur Kreativität bei der Erstellung eigener multimedialer und moderner Unterrichtshilfen animieren. Darüber hinaus dient der Einsatz von ICT auch der Förderung von Kompetenzen in Methodik und Informatik; sie erhöht die Chancen auf den Erwerb neuer Kenntnisse und Fertigkeiten. Mit ICT kann die theologisch-religiöse Ausbildung der Religionslehrer*innen individualisiert und ihr methodisches Instrumentarium erweitert werden. ${ }^{20}$ Sie lernen, wie attraktive und aktivierende Inhalte, Apps oder Lernspiele kostenfrei online erschlossen werden können und wie sich ICT praktisch bei der Erstellung attraktiver Unterrichtskonzepte für den Religionsunterricht einsetzen lassen. ${ }^{21}$

Eine moderne theologisch-religiöse Ausbildung von Religionslehrer*innen ohne ICT ist kaum vorstellbar. Neueste Tendenzen in der Didaktik sowie die Anwendung von digitalen Tools verleihen dem Prozess der einführenden und permanenten Formung einen interaktiven Charakter. Sie vereinfachen die Kommunikation unter allen Beteiligten, stärken die Effektivität des gesamten Prozesses, fördern die Offenheit gegenüber technologischen Neuerungen und verleihen dem gesamten Aus- bzw. Fortbildungsprozess einen innovativen Charakter. ${ }^{22}$

\section{FORMEN DER ICT-BILDUNG FÜR RELIGIONSLEHRER*INNEN}

Die einführende und permanente ICT-Bildung der Religionslehrer*innen sollte mit einer Analyse der Bedürfnisse der künftigen und der bereits beruflich aktiven Lehrkräfte beginnen. Junge Menschen sind bereits in der digitalen

\footnotetext{
${ }^{20}$ Mehr dazu bei Anna ZelLMA, „Cyberprzestrzeń w warsztacie pracy edukacyjnej nauczyciela religii - szansa czy zagrożenia?“ Świat i Słowo 22 (2014): 185-96.

${ }^{21}$ Ebd.

${ }^{22}$ ZELLMA, Profesjonalny rozwój nauczyciela religii, 280, 282-84.
} 
Welt angekommen und werden auch als „digitale Eingeborene“ bezeichnet, was den Religionsunterricht und die theologisch-religiöse Ausbildung vor neue Herausforderungen stellt ${ }^{23}$. Trotzdem ist Wissen über ICT und ihre Anwendung nicht gleichmäßig verteilt. Aus diesem Grunde sollte das Aus- und Fortbildungsangebot für Religionslehrer*innen die unterschiedlichen Erwartungen aller Adressaten berücksichtigen. Anhand einer Analyse kann ein detaillierter Umfang der ICT-Ausbildung bestimmt werden. Dabei geht es sowohl um Inhalte (Themen einzelner Veranstaltungen) als auch um Hinweise auf die Form der Lehrveranstaltungen und die dafür Verantwortlichen. In der permanenten Phase könnten z. B. Fakultäten für Religionspädagogik jedes Jahr einen Fortbildungsplan im Bereich ICT für Religionslehrer*innen ausarbeiten, denn im Bereich moderner Technologien verläuft der Fortschritt rasant. Deswegen ist das Angebot an die jeweils aktuellen und zugleich individuellen Erwartungen zuzuschneiden. Das können etwa Schulungen über die praktische Anwendung von sozialen Medien oder von Lern- und Informationsportalen im Religionsunterricht $\operatorname{sein}^{24}$. Einher ginge damit - während gemeinsamer Treffen - die Vorbereitung eines Verzeichnisses mit Internetseiten, multimedialen Programmen und unterrichtsbegleitenden Materialien für den Religionsunterricht. Doch darauf darf sich die Ausbildung der Religionslehrer*innen im Bereich ICT nicht beschränken. Viel bedeutsamer für die Praxis sind nämlich sowohl die Besprechung als auch das praktische Einüben der Erstellung von Unterrichtsmaterialien mittels ICT. ${ }^{25}$ Notwendig sind also entsprechende methodische Workshops für Katechetinnen und Katecheten. Auch im Rahmen der beruflichen Fortbildung sollten Religionslehrer*innen online in Gruppen arbeiten und so gemeinsam Unterrichtskonzepte erarbeiten können.

Eine andere Möglichkeit der ICT-Ausbildung bieten offene Unterrichtsstunden im Rahmen der kollegialen Hospitation. ${ }^{26}$ Veranstaltungen dieser Art dienen der Präsentation verschiedener Tools und Arbeitsmethoden für den Religionsunterricht an Schulen, die auf dem Einsatz von modernen IC-Technologien basieren. Die Teilnehmenden können so ihre methodischen Erfahrungen und Best-Practice-Beispiele untereinander austauschen.

${ }^{23}$ Siehe dazu etwa Mirosław CHMIELEwSKI, „Nowe media - nowe wyzwania wychowawcze dla katechezy,“ Roczniki Teologiczne 65, Nr. 11 (2018): 127-48.

${ }^{24}$ Dazu Anna ZelLmA, ,Edukacyjne i społecznościowe portale jako nowe przestrzenie w warsztacie pracy i doskonalenia kreatywnego nauczyciela religii“, Roczniki Pastoralno-Katechetyczne, Nr. 4 (2012): 191-206.

${ }^{25}$ Über diese Materialien siehe etwa bei Marek KoRgul, Dydaktyka dla katechetów (Świdnica: Usługi Poligraficzne Bogdan Kokot vel Kokociński, 2014), 165-67, 247-48; Stanisław ŁABENDowICZ, Metodyka katechezy (Radom: Instytut Naukowo-wydawniczy „Spatium“, 2019), 60-68.

${ }^{26}$ Dazu siehe in Zellma, Profesjonalny rozwój nauczyciela, 229-30. 
In diesem Zusammenhang seien auch Schwierigkeiten und Probleme genannt, die bei der Anwendung von modernen IC-Technologien im schulischen Religionsunterricht auftauchen können. Mit Sicherheit sind für die ICT-Ausbildung von Religionspädagogen die erforderlichen technischen Voraussetzungen in Form von entsprechend ausgestatteten Klassenräumen (PCs, Beamer, interaktive Whiteboards, Internetanschlüsse) zu schaffen, was allerdings momentan das geringste Problem zu sein scheint, denn viele Religionslehrer*innen besitzen geeignete mobile Geräte, an den Fakultäten kommen Beamer bereits zum Einsatz und auch interaktive Whiteboards und Internetanschlüsse sind vorhanden. Wichtig ist aber auch der Zugang zu E-LearningPlattformen. Ohne den Zugriff auf geeignete Lernplattformen kann man kaum den Kern, Charakter, Ziele, Grundprinzipien, Inhalte und aktive Methoden von Homeschooling vermitteln. Auch die Entfaltung von Kompetenzen für das selbständige Erstellen von Entwürfen für den Unterricht online bzw. von interessanten Präsentationen (z. B. mit Hilfe des Programms Prezi) setzt ein praktisch erworbenes Wissen voraus. Dies alles können geeignete E-LearningPlattformen gewährleisten. Deshalb sollten die Verantwortlichen an den Fakultäten und in den Fortbildungseinrichtungen alles daransetzen, dass die Studierenden im Zuge der Aus- und Fortbildung im Bereich ICT Zugriff auf verschiedene Plattformen bekommen, die beim E-Learning angewandt werden. $\mathrm{Zu}$ nennen wären hier beispielhaft folgende Angebote: Moodle, LIBRUS Synergia, Google Classroom, ZOOM, Quizlet, Quizizz, Padlet, Storybird, die App Discord sowie Microsoft 365 mit Microsoft Teams. Sie ermöglichen sowohl asynchrone Kommunikationsformen wie E-Mails oder komplexe Diskussionsgruppen als auch synchrone (z. B. Chats). Sie bieten geeignete Tools für Audio- und Videokonferenzen und ermöglichen Lernen und Kooperieren online. Mit ihrer Hilfe können die in der ganzen Diözese oder ganz Polen verstreuten Religionslehrer*innen gemeinsame Projekte vorbereiten oder innovative Maßnahmen durchführen (Unterrichtskonzepte, Multimediamaterialien, Apps für Schüler*innen, Wettbewerbe, QR-Codes, Onlinespiele, E-Aufgaben, E-Hausaufgaben, Wortwolken oder Filme).$^{27}$ Empfehlenswert sind Lernspiele, Aufgaben, Quizfragen, Puzzlespiele, die mit den Apps LearningApps.org und

\footnotetext{
${ }^{27}$ Siehe etwa Bożena SolECKA, Nowoczesne technologie w aktywizowaniu ucznia. Konsultacje nauczycieli $z$ SORE $w$ ramach wspomagania szkoły $w$ rozwoju (Warszawa: Ośrodek Rozwoju Edukacji, 2018); Tomasz RoJEK, „Aplikacje do tworzenia szkolnych quizów“, TIK w edukacji, 24. Oktober 2019, abgerufen am 1. Mai 2020, http://www.tikwedukacji.pl/wydania/pazdziernik-2019/ art,2486,aplikacje-do-tworzenia-szkolnych-quizow.html.
} 
Kahoot! vorbereitet werden. Den Religionslehrer*innen stehen viele Möglichkeiten zur Verfügung, interessante, interaktive Unterrichtshilfen für den Religionsunterricht vorzubereiten. ${ }^{28}$ Allerdings benötigen sie dafür entsprechende Kompetenzen. Das ist eine Aufgabe für die einführende und die permanente Phase der Formung. Auch das Lehrerportal Scholaris stellt unentgeltlich Apps für die Vorbereitung von Multimediatools zur Verfügung. Mit ihrer Hilfe können Texte, Grafiken und externe Dateien (Ton, Filme) eingesetzt und das Wissen und Kompetenzen der Schüler*innen anhand von Onlinetexten überprüft werden. Sie bieten auch die Möglichkeit, Ein- und Mehrfachwahlaufgaben, Wortsalate und Lückenteste zu schreiben. Alle diese Elemente können in der Netzwerkressource „Multimediaunterricht“ miteinander verbunden werden.

Die genannten E-Learning-Formen helfen nicht nur bei der attraktiven Gestaltung des Theologiestudiums und der Fortbildung, sondern fördern auch die Verwendung von ICT. Dafür müssen jedoch einzelne Lehrveranstaltungen in geeigneter Form ablaufen. Deswegen sollte das Programm der Übungen im Theologiestudium und während der Workshops für Religionslehrer*innen um die hier vorgestellten Themen und um moderne Methoden in allen Phasen der theologisch-religiösen Ausbildung ergänzt werden.

\section{POSTULATE}

Es ist offenkundig, dass sich durch die Verwendung von ICT neue Möglichkeiten für die theologisch-religiöse Ausbildung der Religionslehrer*innen in Polen ergeben. Und in der Tat werden sie von den theologischen und religionspädagogischen Fakultäten immer häufiger eingesetzt, wenn auch mit unterschiedlichem Erfolg, denn die Unterschiede sind erheblich und beeinflussen im Nachhinein das Niveau des Religionsunterrichts an polnischen Schulen. Aus diesem Grund ist es wünschenswert, diese Fragen mit den Leitungen der Fakultäten und Institute sowie allen Dozenten zu diskutieren.

Zweifelsohne sollten Fragen der ICT-Ausbildung im Mittelpunkt der Beratungen der Kommission für Katholische Erziehung der Polnischen Bischofskonferenz sowie des Büros für die Planung der Katechese stehen. Beide Gremien sind für die Ausbildung der Katechetinnen und Katecheten in Polen verantwortlich. $\mathrm{Zu}$ ihren Aufgaben gehört es auch, auf die „Zeichen der Zeit“ zu reagieren und neue Richtlinien vorzulegen.

\footnotetext{
${ }^{28}$ Empfehlenswert sind TIK w edukacji: magazyn innowacyjnych nauczycieli i dyrektorów szkót, herausgegeben seit 2016 in Wrocław - im Verlag Presscom Sp. z o.o. Siehe http://www.tikwedukacji.pl.
} 
Wichtig sind auch neue Lehrbücher und methodische Handreichungen. Sie sollten modern sein und den Bedürfnissen der Schüler*innen entgegenkommen. Sie dürfen sich nicht nur auf traditionelle Vermittlungs- und Erziehungsmethoden beschränken. Religionslehrinnen und -lehrern müssen moderne, auch von Internetplattformen abrufbare Unterrichtsmaterialien zur Verfügung stehen. Dabei wären sicherlich E-Lehrbücher und moderne multimediale Materialien überaus hilfreich und lohnend.

Ein weiteres wichtiges Thema ist die Frage nach der Fortbildung von Religionslehrern*innen in den einzelnen Diözesen. Hier darf man sich nicht nur auf herkömmliche methodische Aktivitäten beschränken und muss stattdessen in stärkerem Maße diverse E-Learning-Möglichkeiten einbeziehen. Dazu können auch Experten auch aus anderen Regionen Polens herangezogen werden. E-Learning kann diese Kontakte ermöglichen und helfen, die theologisch-religiöse Ausbildung moderner, effektiver und attraktiver gestalten. Die Verwendung von E-Learning-Plattformen kann für Katechetinnen und Katecheten, insbesondere in der permanenten Formung, in ihrer Arbeit in heutigen Schulen, im digitalen Umfeld, eine große Hilfe bedeuten. E-Learning kommt immer häufiger zum Einsatz. Deshalb stellt die Online-Ausbildung polnischer Religionslehrer heute eine der größten Herausforderungen dar. Sie bietet Chancen, den Religionsunterricht an polnischen Schulen qualitativ auf eine höhere Stufe zu stellen. E-Learning birgt zahlreiche Entwicklungspotenziale in sich und sein Einsatz, sowohl in der einführenden als auch in der permanenten Phase der Ausbildung, sollte intensiv gefördert werden. Dabei gilt es, stets das richtige Verhältnis zwischen dem Erwerb von Wissen und Informationen und ihrer praktischen Nutzung während der Ausbildung und im Schuldienst zu wahren.

\section{LITERATURVERZEICHNIS}

ChMielewski, Mirosław. „Nowe media - nowe wyzwania wychowawcze dla katechezy.“ Roczniki Teologiczne 65, Nr. 11 (2018): 127-48.

„ICT - Technologie informacyjno-komunikacyjne.“ istshare. Abgerufen am 30. April 2020. https:// www.istshare.eu/ict-technologie-informacyjno-komunikacyjne.html.

„Kilka słów o TIK.“ Tik w szkole602642223 (Blog), 17. März 2018. Abgerufen am 30. April 2020. https://tikwszkole602642223.wordpress.com/2018/03/17/kilka-slow-o-tik.

KONGREGATION FÜR DEN KLERUS. Dyrektorium ogólne o katechizacji [Allgemeindirektorium über Katechisierung]. Poznań: Pallottinum, 1998.

Korgul, Marek. Dydaktyka dla katechetów. Świdnica: Usługi Poligraficzne Bogdan Kokot vel Kokociński, 2014.

ŁABENDOwICZ, Stanisław. Metodyka katechezy. Radom: Instytut Naukowo-Wydawniczy „Spatium“, 2019. 
MąKosA, Paweł. „Nauczanie wobec cyfryzacji polskiej szkoły.“ Roczniki Teologiczne 61, Nr. 11 (2014): 25-38.

Polnische BischofSKOnferenz. Dyrektorium katechetyczne Kościoła katolickiego w Polsce [Katechetisches Direktorium der katholischen Kirche in Polen]. Kraków: WAM, 2001.

Porozumienie pomiędzy Konferencją Episkopatu Polski oraz Ministrem Edukacji Narodowej z dnia 3 kwietnia 2019 roku w sprawie kwalifikacji zawodowych wymaganych od nauczycieli religii [Abkommen zwischen der polnischen Bischofskonferenz und dem Ministerium für Nationale Bildung vom 3. April 2019 über die beruflichen Anforderungen an Religionslehrer*innen]. Dziennik Urzędowy MEN [Amtsblatt des Ministeriums für Nationale Bildung] 2019, Pkt. 9.

ROJEK, Tomasz. „Aplikacje do tworzenia szkolnych quizów.“ TIK w edukacji, 24. Oktober 2019. Abgerufen am 1. Mai 2020. http://www.tikwedukacji.pl/wydania/pazdziernik-2019/art,2486, aplikacje-do-tworzenia-szkolnych-quizow.html.

Rozporządzenie Ministra Nauki i Szkolnictwa Wyższego z dnia 25 lipca 2019 r. w sprawie standardu kształcenia przygotowującego do wykonywania zawodu nauczyciela [Verordnung des Ministers für Wissenschaft und Hochschulwesen vom 25. Juli 2019 über Ausbildungsstandards für den Lehrerberuf]. Dziennik Ustaw [Gesetzblatt der Republik Polen] 2019, Pkt. 1450.

Rozporządzenie Ministra Edukacji Narodowej z dnia 26 lipca 2018 r. w sprawie uzyskiwania stopni awansu zawodowego przez nauczycieli [Verordnung des Ministers für Nationale Bildung vom 26. Juli 2018 über die Beförderung von Lehrern]. Dziennik Ustaw 2018, Pkt. 1574.

Rozporządzenie Ministra Edukacji Narodowej z dnia 23 sierpnia 2019 r. zmieniająca rozporządzenie w sprawie uzyskiwania stopni awansu zawodowego przez nauczycieli [Verordnung des Ministers für Nationale Bildung vom 23. August 2019 über Änderungen der Verordnung über die Beförderung von Lehrern]. Dziennik Ustaw 2019, Pkt. 1650.

SEWERYN, Renata. „Technologie informacyjne i komunikacyjne - wprowadzenie w problematyke.“” In Technologie informacyjne i komunikacyjne na rynku turystycznym, hrsg. v. Jadwiga Berbeka und Krzysztof Borodako, 11-30. Warszawa: C.H. Beck, 2017.

SOLECKA, Bożena. Nowoczesne technologie w aktywizowaniu ucznia. Konsultacje nauczycieli z SORE w ramach wspomagania szkoły w rozwoju. Warszawa: Ośrodek Rozwoju Edukacji, 2018.

Ustawa z dnia 26 stycznia 1982 roku - Karta nauczyciela [Gesetz vom 26. Januar 1982 - Lehrercharta]. Dziennik Ustaw 2019, Pkt. 2215.

Ustawa z dnia 7 września 1991 roku o systemie oświaty [Gesetz vom 7. September 1991 über das Bildungssystem]. Dziennik Ustaw 2019, Pkt. 1481, 1818, 2197.

Ustawa z dnia 14 grudnia 2019 r. prawo oświatowe [Gesetz vom 14. Dezember 2019 Bildungsrecht]. Dziennik Ustaw 2019, Pkt. 1148, 1078, 1287, 1680, 1681, 1818, 2197, 2248; 2020, Pkt. 374.

ZAJĄC, Marian. „Możliwość wykorzystania technologii informacyjno-komunikacyjnych w edukacji religijnej“, Biuletyn Edukacji Medialnej, Nr. 2 (2015): 85-96.

Zellma, Anna. „Cyberprzestrzeń w warsztacie pracy edukacyjnej nauczyciela religii - szansa czy zagrożenie?“ Świat i Stowo 22 (2014): 185-96.

Zellma, Anna. „Edukacyjne i społecznościowe portale jako nowe przestrzenie w warsztacie pracy i doskonalenia kreatywnego nauczyciela religii“, Roczniki Pastoralno-Katechetyczne, Nr. 4 (2012): 191-206.

Zellma, Anna. Profesjonalny rozwój nauczyciela religii (Olsztyn: Wydział Teologii Uniwersytetu Warmińsko-Mazurskiego w Olsztynie). 


\title{
ICT IN DER THEOLOGISCH-RELIGIÖSEN AUSBILDUNG POLNISCHER RELIGIONSLEHRER*INNEN
}

\begin{abstract}
Angesichts der Entwicklung von neuen IC-Technologien in Polen und der Digitalisierung des polnischen Schulwesens wurde der Versuch unternommen, ICT im Ausbildungsprozess polnischer Religionslehrer*innen zu verorten. In diesem Zusammenhang wurden katechetische Dokumente der katholischen Kirche in Polen, normative Akte und die Gegenstandsliteratur herangezogen. Erwähnt wurde sowohl die einführende, als auch die permanente theologisch-religiöse Ausbildung. Ferner wurde auch kurz der aktuelle Stand der ICT-Ausbildung von polnischen Katechetinnen und Katecheten dargestellt. Des Weiteren wurden auch der Stellenwert und die Funktion von ICT in der Ausbildung von Religionspädagogen in Polen analysiert. Daraus ging hervor, dass ICT in diesem Prozess einen besonderen Platz einnimmt. ICT ist unverzichtbar, denn nur so können Religionslehrer*innen ihre Kompetenzen im Bereich Informatik entfalten. Ferner wurden aktuelle E-Learning-Möglichkeiten dargestellt. Es wurde nachgewiesen, welche organisatorischen und methodischen Möglichkeiten ICT für die Arbeit in der Schule eröffnet und wie wichtig die Arbeit mit E-Learning-Plattformen (z. B. Storybird, Padlet, Story Dice) sowie die Ausarbeitung und Anwendung von zahlreichen Apps (LearningApps.org, Kahoot!) sein kann.
\end{abstract}

Schlüsselwörter: Religionsdidaktik; Religionslehrer*in; Katechet*in; theologisch-religiöse Formung; IC-Technologien; E-Learning.

\section{TIK WE WSPÓŁCZESNEJ FORMACJI POLSKICH KATECHETÓW}

\section{Streszczenie}

W obliczu rozwoju nowych technologii informacyjno-komunikacyjnych w Polsce i cyfryzacji polskiej szkoły podjęto próbę ukazania TIK we współczesnej formacji polskich katechetów. Odwołano się do dokumentów katechetycznych Kościoła powszechnego i w Polsce, aktów normatywnych oraz literatury przedmiotu. Zwrócono uwagę zarówno na wstępną, jak i permanentną formację. W tym celu dokonano krótkiej prezentacji obecnego stanu formacji katechetów w Polsce w zakresie TIK. Następnie analizowano miejsce i funkcje TIK w formacji polskich katechetów oraz sposoby jej realizacji w zakresie TIK. Przeprowadzona analiza dowiodła, że we współczesnej formacji polskich katechetów TIK zajmuje szczególne miejsce.

Nie może go zabraknąć, gdyż tylko w ten sposób katecheci mogą kształtować umiejętności informatyczne. Jednocześnie przedstawiono szereg możliwości e-learningowych. Ukazano także możliwości organizacyjne i metodyczne jakie TIK niesie dla pracy katechetów w szkole. Za ważne uznano m.in. umiejętności pracy na platformach zdalnego nauczania (np. Storybird, Padlet, Story Dice) oraz tworzenia i zastosowania różnych aplikacji (np. LearningApps.org., Kahoot!).

Słowa kluczowe: dydaktyka katechezy; katecheta; formacja; technologie informacyjno-komunikacyjne; e-learning. 